\title{
Retrospective Analyses of Frequent Emergency Department Users
}

\author{
(1) Gülșah Çıkrıkçı Ișık, (1) Meral Tandoğan, (1) Tuba Şafak, (1) Yunsur Çevik \\ Clinic of Emergency Medicine, University of Health Sciences Turkey, Keçiören Training and Research Hospital, Ankara, Turkey
}

\begin{abstract}
Aim: Emergency department (ED) demand and overcrowding is increasing worldwide, and a significant portion of this overcrowding is caused by "frequent users". The aim of the study is to define the characteristics of this group of patients who contribute towards a disproportionate number of ED visits.

Materials and Methods: All ED visits during a 1-year period between 01 January 2018 and 31 December 2018 were retrospectively investigated using the electronic registration system of the hospital. Patients who visited the ED $\geq 4$ times in this period were considered as "frequent users". Social history, disease and care-related factors of frequent users were investigated.

Results: A total of 335,457 ED visits made in a calendar year (2018) were investigated. Frequents users comprised 6.8\% of all ED patient population and $22.9 \%$ of all ED visits. Female gender proportion was greater among frequent users, and frequent users were younger than occasional users. Yellow/red triage code ratio was higher and the median length of hospital stay was significantly longer in the frequent users group. The proportion of uninsured patients was two times higher in the frequent users group, and half of these patients were immigrants or refugees.

Conclusion: Frequent users place a significant burden on the increasing patient volume in EDs. Welfare status was an important indicator for being a frequent user. However, frequent users are a very heterogeneous patient group and more research is needed to better understand the factors leading to frequent ED use and to develop effective strategies to meet patients' complex health care needs.
\end{abstract}

Keywords: Frequent users, occasional users, emergency department

\section{Introduction}

Increased emergency department (ED) demand and overcrowding of ED's is a global healthcare system problem $(1,2)$. Data demonstrated that ED use grew by $36 \%$ in a decade in the United States (3). For Turkey, the situation is more dramatic that the annual number of ED visits is greater than the whole population (4). A significant portion of this overcrowding was created by "frequent users", a group of patients who contribute toward a disproportionate number of ED visits (5). Recognition of this group of patients is very important in terms of health policies and emergency literature, because frequent users make up nearly one fourth of all ED visits and so use a large number of medical resources (6).

Definition of frequent users varies in different studies; however four or more ED visits annually is accepted as an effective cut-off value to identify this group of patients $(6,7)$. Those are a very heterogeneous group with medical insurance, multiple chronic diseases, chemical dependence, and mental health issues (8). While representing 4-8\% of ED patients, frequent users, account for $21-28 \%$ of all ED visits (9). Studies also demonstrated that approximately $20-40 \%$ of frequent users in one year remain frequent users in the following year (9). Those numbers prove us frequent users are what a huge burden for emergency departments.

For the perception of health professionals, frequent users most of the time present with non-urgent and undue complaints, so their care is considered to be a waste of time and an inappropriate use of ED resources (10). At the policymaker's point of view frequent users are causing a significant health burden and reducing the number of them as a means of decreasing healthcare costs (11). On the other hand, some studies demonstrated that frequent

Cite this article as: Çıkrıkçı Ișık G, Tandoğan M, Șafak T, Çevik Y. Retrospective Analyses of Frequent Emergency Department Users. Eurasian J Emerg Med. 2020;19(2):89-93 
users have poorer health compared to occasional users with the high prevalence of chronic diseases that lead to increased ED use, and high rates of hospitalization and mortality (10). Therefore, defining the characteristics of this group is a necessity to allow clearly directed policy design for decreasing ED burden caused by the frequent use and also meet the true medical needs of the frequent users. So, the aim of this study is to define the characteristics of frequent users in order to provide efficient and cost-effective suggestions for solving this healthcare system problem.

\section{Materials and Methods}

This study was conducted in University of Health Sciences Turkey, Keçiören Training and Research Hospital training and research hospital in capital with around 335000 annual number of ED visits after approval of the local ethics committee. All ED visits during 1-year period between 01.01.2018 and 31.12.2018 were investigated retrospectively by using electronic registration system of the hospital. Patients attended to $E D \geq 4$ times between these periods were accepted as "frequent user" and included into the study. Number four is determined according to previous studies (6). As a subgroup, patient attended $\geq 12$ times in a year were called as "super users". Because the emergency department admittance numbers are very high in our country, we added a new definition to describe the patient attended $\geq 24$ times in a year and called them as "hyper users". Patient with less than 4 attendance in a year defined as "non-frequent users" and patient admitted to ED for wound dressing and prescript drug injection were excluded.

Social-history related factors (age, gender, and ethnicity), disease related factors (diagnosis, severity of illness as triage code, average length of stay at ED) and care related factors (insurance status, cost) were investigated. Diagnostic codes of patient were categorized in ten groups according to systems as: nonspecific/pain related complaints (nonspecific pain, fatigue, and myalgia), respiratory complaints (upper respiratory tract infections, lower respiratory tract infections, asthma, chronic obstructive pulmonary disease), gastrointestinal complaints (abdominal pain, gastroenteritis, nausea, vomiting etc.), psychiatric complaints (suicide, anxiety), neurological complaints (headache, vertigo, stroke, epilepsy etc.), cardiac complaints (chest pain, heart failure, palpitation etc.), trauma (stab wounds, burn, bone fractures, soft tissue injuries etc.), obstetric and gynecologic complaints, urinary complaints [(renal colic, urinary tract infections, renal failure) and others.

\section{Statistical Analysis}

The statistical analysis was performed using the IBM SPSS Statistics for Windows Version 22.0 (IBM Corp. Armonk, NY: USA.
Released 2013). After assessing normal distribution using the Kolmogorov-Smirnov test, all variables were described in terms of median and interquartile range (IQR) (25-75\%) and categorical variables defined as number and frequencies. Mann-Whitney $U$ test and chi-square test were used to determine the difference between the groups. A p value $<0.05$ was considered statistically significant.

\section{Results}

A total of 335457 ED visits were made in a calendar year of 2018 and when the visits for wound dressing and injection were removed the real ED admittance number was 282586 from a total of 172120 different patient. Total visit number of frequent users was 64651 and total number was 11667 patients (visit ED $\geq 4$ times in a year). That means $6.8 \%$ of ED patient population makes the $22.9 \%$ of all ED visits.

Subgroups of frequent users were analysed and 385 of those frequent users were super user (visit ED $\geq 12$ times in a year) and 45 of those super users were hyper user (visit ED $\geq 24$ times in a year). Highest visit number of one patient was 169 in the flow chart (Figure 1).

Among those, 64651 admittance, 40930 (63.3\%) were female and median age of frequent users was 35 (IQR 26-49). Those variables were significantly different from the non-frequent visit group. Female admittance was higher and median age was younger at the frequent visit group ( $p<0.001$ for both situations). Ninetyeight percent $(n=63241)$ of the frequent visits were done by Turkish citizens and only 1410 visits were done by foreigners most of whom were from Iraq $(n=1196)$ (Table 1).

Triage codes of frequent visit were investigated; $78.6 \%$ had green triage code and there were only 19 visits with red triage code.

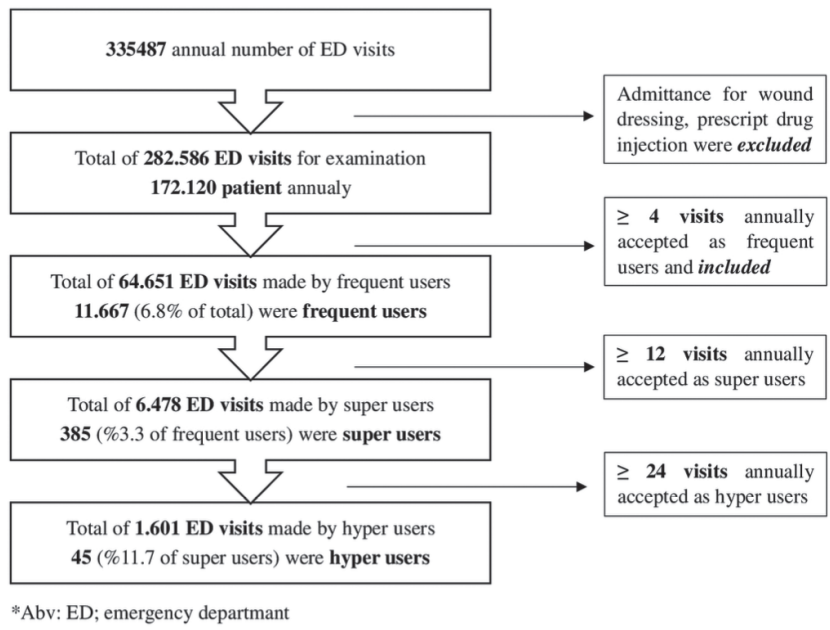

Figure 1. Flow chart 
$(5,6)$. On the other hand, some studies stated the frequent users were significantly younger than the non-frequent users (12). In general, it can be mentioned that age and gender were not significant predictors of frequent ED use (12). Nevertheless, our study showed that ratio of female was higher at frequent users group, and frequent users were younger than the non-frequent users.

There is a concern that frequent users ED use might be inappropriate and they were more likely to present with primary care complaints (1). This might be due to the misunderstanding of the medical necessity. According to a study $61 \%$ of patients stated that feeling like their health problem was emergent as to visit ED that day (6); however studies demonstrated there was a difference between frequent users' perceptions of their medical complaint and actual triaged severity; the majority of the frequent users presented to the ED with complaints that would not be considered a medical emergency (3). On the other hand, there were also studies reporting frequent ED users tend to be sicker than occasional users and experience higher mortality, hospital admissions and outpatient visits $(11,13)$. About medical issues it was demonstrated that frequent users were more likely to have chronic diseases, mental illnesses or substance abuse (12). Our study showed the most common complaints of frequent users were pain related, respiratory or gastrointestinal; but unfortunately, this was a retrospective study and the accuracy of the registered diagnostic codes were questionable. On the other hand, frequent users' attendance with yellow triage code was higher and median length of stay was longer than occasional users. These results might be interpreted as the frequent users have higher acuity complaints.

Anyone can make free use of the emergency services in Turkey, therefore the group mentioned in the study as uninsured was in fact dependent on government welfare. This situation was considered as a risk of frequent ED use in some studies $(1,14)$. Similarly, depending on government welfare, immigrant and refugees may use ED free of charge. There were also other reasons that lead immigrants to ED such as language barriers and lack of accessing to primary care providers (15-17). Those reasons explain the high proportion of immigrant and refugees $(8.7 \%)$ in frequent users in our study.

A number of interventions aimed at reducing the number of ED visits by frequent users have been evaluated in the literature; some of them were case management, individualized care plan and information sharing (18). Case management, which is a comprehensive, interdisciplinary approach taken to assess, plan, personalize, and guide an individual's health services to promote improved patient and health system outcomes, seems effective to reduce ED usage of frequent users and improve both clinical and social outcomes among them (19-21). Individualised care plans were similar to case management but less comprehensive that, they employ interdisciplinary strategies and coordinated access to primary care resources (18). Although lack of access to primary care resources seems to be a risk for being frequent ED user, some studies demonstrated that frequent use of the ED might not be related to lack of a listed primary care provider, and that even frequent ED users were also frequent primary care visitors $(22,23)$. Despite comparable primary care access, frequent users were most likely to report unmet primary care needs and further research was necessary to understand and meet the needs of these individuals (23). Lastly, the term "information sharing" was used to describe approaches related to the sharing of patient information amongst health care providers; however, it did not make any sense to decrease the frequent visits (18).

\section{Study Limitations}

The main limitation of this study was being single-centred and the information about frequent visits to other emergency departments could not be obtained, so the actual number of frequent users might be greater than the calculated one. Second, this was a retrospective study and we had no information about the clinical presentations during the ED visits. Data based on the electronic registration system so accuracy of the diagnostic codes were questionable. This made it impossible for us to find out whether chronic diseases affect frequent ED use. Third, some socio-economic data were not available, and such data could be vital for describing the characteristics of ED users.

\section{Conclusion}

The use of emergency services is increasing, and frequent users place a significant burden on this patient volume. It is important to understand the characteristics of this patient group in order to provide efficient suggestions for solving this healthcare problem. In our study, female gender proportion was greater among frequent ED users and frequent users were younger than occasional users. There was also significant difference about welfare status that immigrant and refugees population in frequent users was eighty times higher than the occasional users. However frequent users are a very heterogeneous group and it is impossible to define all the characteristics of them in one study. Therefore, more research is needed in order to better understand factors leading to frequent ED use and to develop effective strategies to better meet their complex health care needs.

\section{Ethics}

Ethics Committee Approval: This study was approved by University of Health Sciences Turkey, Keçiören Training and Research Hospital Chief Surgeon Office, Clinical Research Ethics Committee (decision no: 2012-KAEK-15/1951, date: 28.08.2019). 
Informed Consent: Retrospective study.

Peer-review: Externally peer-reviewed.

\section{Authorship Contributions}

Concept: G.Ç.I., T.Ş., Design: G.Ç.I., T.Ş., Data Collection or Processing: G.Ç.I., M.T., Analysis or Interpretation: G.C..I., M.T., Literature Search: G.Ç.I., M.T., T.Ș., Y.Ç., Writing: G.Ç.I.

Conflict of Interest: There is no conflict of interest for this paper.

Financial Disclosure: This research did not receive any specific grant from funding agencies in the public, commercial, or notfor-profit sectors.

\section{References}

1. Ko M, Lee Y, Chen C, Chou P, Chu D. Prevalence of and Predictors for Frequent Utilization of Emergency Department: A Population-Based Study. Medicine (Baltimore). 2015;94:e1205.

2. Nambiar D, Stoové M, Dietze P. Frequent emergency department presentations among people who inject drugs: A record linkage study. Int J Drug Policy. 2017;44:115-20.

3. Burns TR. Contributing factors of frequent use of the emergency department: A synthesis. Int Emerg Nurs. 2017;35:51-5.

4. Solakoglu GA, Karakilic ME, Aciksari K. Frequent attenders to emergency department in a research hospital in Turkey. Medeniyet Medical Journal. 2018;33: 158-66.

5. van Tiel S, Rood PP, Bertoli-Avella AM, Erasmus V, Haagsma J, van Beeck E, et al. Systematic review of frequent users of emergency departments in non-US hospitals: state of the art. Eur J Emerg Med. 2015;22:306-15.

6. Birmingham LE, Cochran T, Frey JA, Stiffler KA, Wilber ST. Emergency department use and barriers to wellness: a survey of emergency department frequent users. BMC Emerg Med. 2017;17:16.

7. Norman C, Mello M, Choi B. Identifying Frequent Users of an Urban Emergency Medical Service Using Descriptive Statistics and Regression Analyses. West J Emerg Med. 2016;17:39-45.

8. Castillo EM, Brennan JJ, Killeen JP, Chan TC. Identifying frequent users of emergency department resources. J Emerg Med. 2014;47:343-7.

9. Kanzaria HK, Niedzwiecki MJ, Montoy JC, Raven MC, Hsia RY. Persistent Frequent Emergency Department Use: Core Group Exhibits Extreme Levels Of Use For More Than A Decade. Health Aff (Millwood). 2017;36:1720-8.
10. Acosta AM, Lima MA. Frequent users of emergency services: associated factors and reasons for seeking care. Rev Lat Am Enfermagem. 2015;23:33744.

11. LaCalle E, Rabin E. Frequent users of emergency departments: the myths, the data, and the policy implications. Ann Emerg Med. 2010;56:42-8.

12. Krieg C, Hudon C, Chouinard MC, Dufour I. Individual predictors of frequent emergency department use: a scoping review. BMC Health Serv Res. 2016;16:594.

13. Moe J, Kirkland S, Ospina MB, Campbell S, Long R, Davidson A, et al. Mortality, admission rates and outpatient use among frequent users of emergency departments: a systematic review. Emerg Med J. 2016;33:230-6.

14. Bieler G, Paroz S, Faouzi M, Trueb L, Vaucher P, Althaus F, et al. Social and medical vulnerability factors of emergency department frequent users in a universal health insurance system. Acad Emerg Med. 2012;19:63-8.

15. Saunders NR, To T, Parkin PC, Guttmann A. Emergency Department Revisits by Urban Immigrant Children in Canada: A Population-Based Cohort Study. J Pediatr. 2016;170:218-26.

16. Mahmoud I, Eley R, Hou XY. Subjective reasons why immigrant patients attend the emergency department. BMC Emerg Med. 2015;15:4.

17. Ruud SE, Hjortdahl P, Natvig B. Reasons for attending a general emergency outpatient clinic versus a regular general practitioner - a survey among immigrant and native walk-in patients in Oslo, Norway. Scand J Prim Health Care. 2017;35:35-45.

18. Soril LJ, Leggett LE, Lorenzetti DL, Noseworthy TW, Clement FM. Reducing frequent visits to the emergency department: a systematic review of interventions. PLoS One. 2015;10:e0123660.

19. Bodenmann P, Velonaki VS, Griffin JL, Baggio S, Iglesias K, Moschetti K, et al. Case Management may Reduce Emergency Department Frequent use in a Universal Health Coverage System: a Randomized Controlled Trial. J Gen Intern Med. 2017;32:508-15.

20. Grover CA, Crawford E, Close RJ. The Efficacy of Case Management on Emergency Department Frequent Users: An Eight-Year Observational Study. J Emerg Med. 2016;51:595-604.

21. Kumar GS, Klein R. Effectiveness of case management strategies in reducing emergency department visits in frequent user patient populations: a systematic review. J Emerg Med. 2013;44:717-29.

22. Palmer E, Leblanc-Duchin D, Murray J, Atkinson P. Emergency department use: is frequent use associated with a lack of primary care provider? Can Fam Physician. 2014;60:223-9.

23. Cunningham A, Mautner D, Ku B, Scott K, LaNoue M. Frequent emergency department visitors are frequent primary care visitors and report unmet primary care needs. J Eval Clin Pract. 2017;23:567-73. 